\title{
A Stitch in Time? Craftivism, Connection and Community in the Time of COVID-19
}

\author{
Nikki Sullivan
}

The Centre of Democracy (CoD) is a distributed museum which has a permanent gallery in Adelaide, South Australia, and extends its presence through online and temporary physical spaces. Its mission is to share stories about democracy in South Australia and to motivate and support individuals and communities to play an active role in changemaking. The second of these aims was central to a public engagement project titled Stitch \& Resist which we began developing in late 2019. In March 2020, just days before we were due to launch the project, COVID-19 hit. Along with the other museums run by the History Trust of South Australia, CoD was closed, public events were cancelled, and we started to talk about 'pivoting' - what it meant and what it might look like in practice. How, we wondered, could CoD remain relevant and useful during lockdown? How might we facilitate discussions around issues that the pandemic and the measures introduced to 'flatten the curve' were bringing to the fore: housing and homelessness, isolation, wellbeing, domestic violence, racism and inequality, to mention but a few? And how might we collect around and document what will undoubtedly prove to be a historically significant moment? Stitch \& Resist has become a vehicle through which we have explored and responded to these questions and the challenges and opportunities that COVID-19 has engendered. Since we are unable to determine the future, we imagine that the project will continue to shape-shift.

The inspiration for Stitch \& Resist came from many sources, key among them, the Tiny Pricks Project, ${ }^{1}$ and Tal Fitzpatrick's craftivism manifesto. Tiny Pricks is a craftivist project created and curated by Diana Weymar to counterbalance the impermanence of social media and in particular Donald Trump's use of it. The project archives Trump's problematic statements that too often disappear as quickly as they are made (although, of course, their effects do not), and in doing so holds him accountable to present and future generations. Trump's words are captured in textile art pieces crafted by hundreds of participants around the globe. The works demonstrate a variety of levels of technical skill but even the most simple contributes powerfully to the larger undertaking. Tal Fitzpatrick's work and her handbook, Craftivism: A Manifesto/ Methodology (Fitzpatrick 2018), likewise demonstrate how craft can be strategically deployed to tackle injustice, foster connection and community, contribute to wellbeing and document historical struggles. A poignant example of this is the UDHR Quilt Project that Fitzpatrick and Stephanie Dunlap ran, in which 131 artists, representing 45 countries, each created a quilt square featuring one of the articles from the Universal Declaration of Human Rights. The four quilts which were produced, and which are now in the collection of the Museum of Australian Democracy, document and address the wrongs that led to the creation of the UDHR and the undermining of democratic and human rights that is currently taking place globally. For both Fitzpatrick and Weymar, craftivism performs democracy, at once inviting participation from everyone and challenging the denigration of 'craft' as 'not art', and as a trivial, apolitical pastime associated with women, indigenous peoples and other minorities.

Inspired by Fitzpatrick and Weymar's work, CoD staff designed a project, centred around the beginner-friendly medium of cross-stitching, which would provide individual changemakers, community groups and organizations with tools and resources to create textile art that addresses its makers' hopes and concerns. Our initial plan was to roll the project out via three avenues: CoD-run public workshops; closed workshops run by partner organizations for clients and members; and an online resource pack that anyone anywhere could use to 
participate in the project, or simply for their own purposes. ${ }^{2}$ In the development stages of the project we approached local community groups and organizations whom we hoped would work with us to address a range of social issues. Of the eleven that accepted our invitation, those who work directly with clients/members agreed to run workshops, whereas others agreed to assist with resources and messaging. All, we hope, will be part of the team that co-creates a Stitch \& Resist exhibition when the relaxing of restrictions around COVID-19 makes this possible. The aim of the workshops was three-fold: to facilitate active citizenship through the creation of political statements in cross stitch; to create safe spaces for discussion and for compassionate listening; ${ }^{3}$ and to contribute to building and nurturing connection, community and wellbeing. Our partner organizations each nominated a facilitator who would run the closed workshops and/or work with CoD staff to develop messages that others would stitch, and a Facilitators' Group was formed which would meet regularly to discuss challenges, wins, progress, issues that had arisen in the workshops and so on.

When the Declaration of a Major Emergency was made in South Australia on 22 March 2020, much of what we had planned was no longer possible. The public Stitch \& Resist workshops that CoD had scheduled were cancelled, ${ }^{4}$ as were those that were to be hosted by partner organizations. Discussions with Tal Fitzpatrick, who had come onboard prior to the appearance of COVID-19, led to the decision to refocus Stitch \& Resist in such a way that the project would engage with and document the impact of the pandemic and its handling, as well as social issues that were of concern prior to the appearance of COVID-19 and that might have been exacerbated by it. The question that drove the project from this point on was: How can we continue to resist injustice, engage in the everyday practice of democracy, and take care of our wellbeing in the midst of a pandemic?

During the first month of lockdown we established regular Zoom meetings with the facilitators from our partner organizations and set up a private Facebook group where we could post work and stories that inspired us, run ideas past each other or, when we needed, just reach out for a chat. As social isolation and online hangouts became the 'new normal', we discussed the possibility of online workshops, and of ways to maintain connection and share ideas and works with community members who don't have access to, or do not want to use, digital technologies. We established 'buddy systems' to ensure that everyone involved was kept in the loop, had regular contact, and could be supported by others. These included regularly calling members who couldn't attend online meetings, and sending out messages, resources, photographs of works and so on, via postal mail. Some buddies uploaded photographs of stitching done by others who weren't comfortable using Facebook or web portals. Throughout this process relationships flourished within, between and across participating organizations: one of our members has shared her knowledge of fabric dying, while others have created pieces addressing issues that they had not previously known much about. Resources, ideas and connections have been shared, together with funny stories, troubles and hopes for a better post-COVID world. The original deadlines have been extended (at this stage indefinitely) and as a result we have more time to discuss, reflect on and respond creatively to the issues that arise and shift as the pandemic unfolds.

Over the last three and a half months Stitch \& Resist has morphed and grown in ways we could not possibly have anticipated and much of this is due to the pandemic and the needs and affordances it has created. We quickly learned from one of our partner organizations which runs a regular Zoom discussion of feminist topics at which some members stitch - that even those who do not want to stitch can play a role: sketching designs, creating patterns or just sharing ideas and words that can become messages for others to stitch. This idea has been taken up by other partners and has led to an increase in participants. Some of the communities served by partner organizations have been particularly hard hit by unemployment and visa status, which makes their members ineligible for certain kinds of government support. In cases where feeding the community is of primary concern, stitching has been put on the back burner. Nevertheless, facilitators have continued to attend meetings, share information about their communities' needs, and seek material and emotional support. For example, one group member told us about a refugee group associated with her organization who are making beanies for their community members; in response, other facilitators put out calls for, collected 
and/or donated wool. The knowledge gained and relationships forged are genuine and will undoubtedly open future possibilities that we cannot, as yet, imagine. We are confident that when the time is right, these communities will produce and share work that, like the pieces currently being uploaded to the Stitch \& Resist online gallery, will become part of the History Trust of South Australia's collections, either digitally or in their original form.

Perhaps the biggest lesson for me has been around loosening the reins and welcoming the ability of communities to determine for themselves what is relevant, how and when. I have learned in practice what I knew in theory but had perhaps never really been tested on: that process is so much more important than tangible outcomes such as exhibitions or cross-stitched political messages. I have learned that when you stop focusing on 'the plan' and obstacles impeding its smooth unfolding, you come to see, value, and, hopefully, foster unexpected connections, insights and potentialities that organically emerge. It's a bit like taking time to stop and smell the roses - something that the pressures associated with meeting deadlines, calculating impact, reporting on metrics, and so on, too often render us impervious to. There is little doubt that the pandemic has had devastating consequences, but Stitch \& Resist has provided an opportunity through which to glimpse silver linings.

Received: 27 June 2020

Finally accepted: 7 July 2020

\section{References}

Fitzpatrick, T. (2018) Craftivism: A Manifesto/Methodology, Melbourne: Blurb.

\section{Notes}

1 https://www.tinypricksproject.com/, accessed 13 April 2020.

2 The resource pack is available on the Stitch \& Resist website - www.stitchandresist.com

3 One of our project partners is an organization called Just Listening which produces resources to support compassionate listening, that is, listening to hear rather than to respond. https://www.justlistening.com.au/

4 Consequently we put more energy into developing our online presence: we set up Facebook and Instagram accounts for the project; joined a large number of Facebook craftivists and textile art groups with whom we shared information about our project; made a series of short videos connecting Stitch \& Resist to our collections and used \#MuseumFromHome to tie the project to a larger global network; started a blog; and took every opportunity that arose to make people aware of our website and online gallery.

\section{Author}

Nikki Sullivan

Centre of Democracy

University of Adelaide

Australia

nsullivan@history.sa.gov.au

Nikki Sullivan is Manager, Centre of Democracy and Adjunct Associate Professor, Faculty of Arts, University of Adelaide. She is the co-author (with Craig Middleton) of Queering the Museum (Routledge, 2019) 